\title{
Mechanical Efficiency of Planetary Gear Trains: An Estimate
}

\author{
Dr. A. Srinath \\ Professor, Dept. of Mechanical Engineering \\ K L University, A.P, India \\ E-mail: srinath_me@klce.ac.in \\ G. Yedukondalu \\ Assistant Professor, Dept. of Mechanical Engineering \\ K L University, A.P, India \\ E-mail: yedukondalu@kluniversity.in \\ Dr. A. Jagadeesh \\ Group Director, GD Rungta College \\ Kohka Kurud Road, Bhilai, Chhattisgarh, India \\ E-mail: jagadeesh.anne@gmail.com
}

Received: November 20, 2011

Accepted: November 29, 2011 Published: December 31, 2011

doi:10.5539/mer.v1n1p97

URL: http://dx.doi.org/10.5539/mer.v1n1p97

\begin{abstract}
In this paper an easy method is presented to estimate the mechanical efficiency of a gear-train-when the number of teeth on gear wheels is specified. Also, the influence of the structure is included in estimating the efficiency. This helps in comparing the gear trains for mechanical efficiency.
\end{abstract}

Keywords: Gear Trains, Mechanical efficiency, Graph theory, Transmission, Friction

\section{Introduction}

Methods for generating distinct planetary gear trains with the specified elements or gear pairs are available (F. Buchsbaum \& F. Freudenstein, 1970; R. Ravisanker \& T. S. Mruthyunjaya, 1985; L. W. Tsai, 1989; C. H. Hsu \& J. J. Hsu, 1997). Also, some methods are available to estimate number of the transmission efficiency of gear trains. These methods are mathematically more rigorous and do not lead to a quick estimate. In the present paper a semi-empirical method is proposed to estimate the mechanical efficiency of a planetary gear train. The mechanical efficiency not only depends upon the size of the gear wheels but also on their relative arrangement i.e., structure. This aspect is also considered. This method gives reasonably good results. The structure of a gear train is best represented by a graph and hence the use of graphs is explained.

\section{Method}

Assuming that there is no power loss at bearings and the entire power loss is due to gear pairs only, the efficiency of a simple gear train can be expressed by the relation (M.F. Spotts),

$$
E=1-\frac{\pi \cdot f\left(N_{1}+N_{2}\right)}{N_{1} N_{2}}
$$

Where, $E$ is the mechanical efficiency of a gear pair, $f$ is the coefficient of friction, $N_{1}$ and $N_{2}$ are the number of teeth on the mating wheels.

As per (J. E. Shigley, Miscke, 2003), the eq. (1) is an excellent approximation. From eq. (1) it is devious that the efficiency of a gear pair is maximum when $\mathrm{N}_{1}=\mathrm{N}_{2}$, In other words, great variation in the number of teeth leads a great reduction in the transmission efficiency.

Eq. (1) is useful in estimating the transmission efficiency of every gear pair in a gear train. In order to estimate the 
transmission efficiency of a gear train as a whole, in which the gear pairs are arranged differently i.e structure of a train, the following approach that uses graph theory is proposed.

\section{Graph Representation of Gear-Trains}

A graph consists of vertices and edges. A vertex is represented by a small circle while an edge is represented by a line joining the vertices. An element of a gear train such as a gear wheel or a carrier is represented by a vertex of a graph while the joints between various elements of a gear train area represented by edges. In gear trains, we have two types of pairs (i) turning pairs and (ii) gear pairs. In order to differentiate the turning and gear pairs, turning pair edges are represented by a single line edge while a gear pair is represented by a double line edge. For example the gear trains shown schematically in figure.1 (a) is represented by the graph, figure. 1(b), $\mathrm{N}_{2}$ and $\mathrm{N}_{3}$, the number of teeth are shown in both the figures $1(\mathrm{a} \& \mathrm{~b})$.

The efficiency $E_{i j}$ of each gear pair ( $\left.i-j\right)$ with specified number of teeth can be estimated using eq.(1) and the same can be shown near the gear pair, figure 1 example, $E_{23}$,

\section{Application to Gear Trains}

The simple gear train figure.1 has three elements or three vertices. Next group of gear trains consist of four vertices or two gear pairs. There are only two distinct gear trains with four elements. They and their graphs are shown in figures 2 and 3. Knowing the teeth numbers of gear wheels the efficiency of each gear pair (2-3) and (2-4) in case of figure. 2 and gear pairs (1-3) and (2-4) in figure. 3 can be determined using eq. (1). The resulting efficiencies $E_{23}$, $\mathrm{E}_{24}$ etc. are shown on the graphs, figures $2 \& 3$.

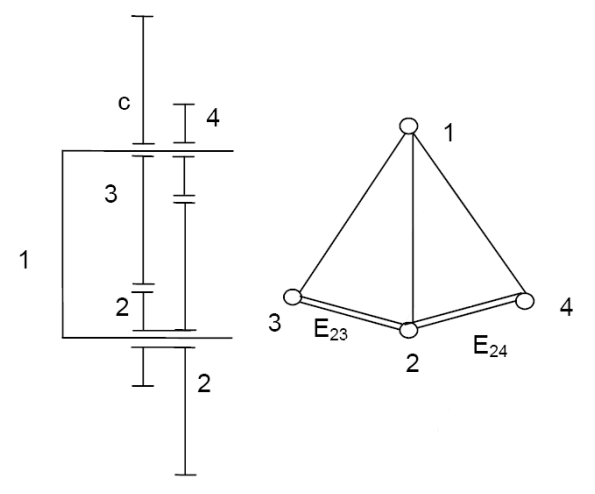

Figure 2. Gear Train consisting of 4 elements-First Type
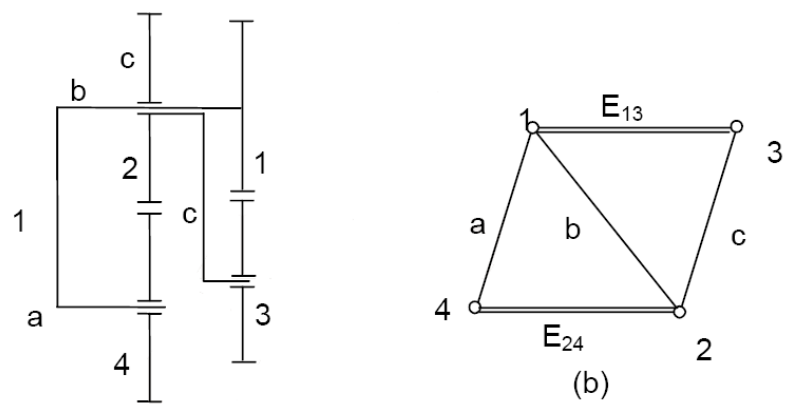

(b)

Figure 3. Gear Train consisting of 4 elements-Second Type

\section{Efficiency Estimate}

Efficiency of a system with components having efficiency $E_{1}, E_{2}$ etc. will depend upon the structural arrangements i.e. whether the components are (i) in series (ii) in parallel or (iii) mixed. The estimate of the system efficiency is explained below.

(i) Efficiency of a series system: 


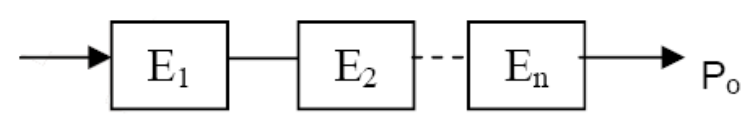

Figure 4. Arrangement of Efficiencies in a Series system

Figure 4 shows $n$ components with efficiencies $\mathrm{E}_{1}, \mathrm{E}_{2}$ etc. arranged in series. It can easily be derived that the overall efficiency $\mathrm{E}$ or the system is equal to the product of the component efficiencies, i.e.,

$$
\begin{aligned}
\mathrm{E} & =\mathrm{E}_{1} \cdot \mathrm{E}_{2} \ldots \ldots \ldots \mathrm{E}_{\mathrm{n}} \\
& =\pi^{n} E_{i} \\
\mathrm{i} & =1
\end{aligned}
$$

(ii) Efficiency of a parallel system:

Figure 5 shows n-components with efficiencies $\mathrm{E}_{1}, \mathrm{E}_{2}$ etc. arranged parallely.

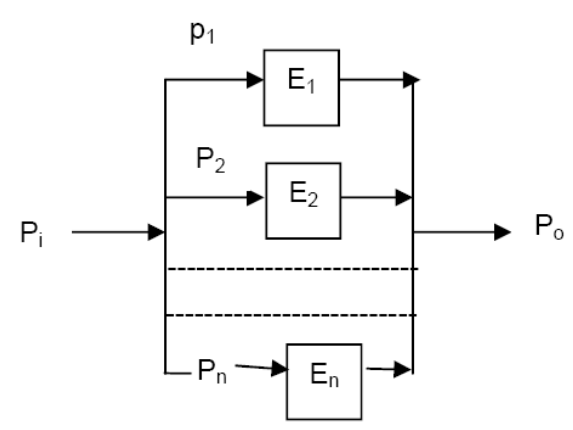

Figure 5. Arrangement of Efficiencies in a Parallel system

The components in parallel will share the input power and let the power in different components be $\mathrm{P}_{1}, \mathrm{P}_{2}$ etc.

Then, the output from each components will be $\mathrm{E}_{1} \mathrm{P}_{1}, \mathrm{E}_{2} \mathrm{P}_{2}$ etc. so that $\mathrm{P}_{0}$ the output power can be expressed as follows,

$$
P_{0}=\sum_{i=1}^{n} E_{i} \cdot P_{i}
$$

Where

$$
\text { E, the system Efficiency }=\frac{P_{0}}{P_{i}}=\frac{\sum_{i=1}^{n} E_{i} P_{i}}{P_{i}}
$$

When greater part of the input power flows through the components of higher efficiency resulting efficiency $E$ of the system will be high and vice-versa. On the other hand if the input power is shared equally among all the components,

$$
E=\frac{1}{n} \sum_{i=1}^{n} E_{i}
$$

For the efficiency values of gear pairs which are high in practice, the system efficiency is not very much sensitive to the power sharing among different circuits or gear pairs. Hence the system efficiency can be taken approximately equal to the average of the component efficiencies, eq. (4).

(iii) Mixed System:

In a mixed system, the combined efficiency of the components in series can be pairs such as (2-3) and (2-4) in figure 
2 should be taken in series so that their combined efficiency is $\left(\mathrm{E}_{23}, \mathrm{E}_{24}\right)$.

Gear pairs (1-3) and (2-4) in Figure.3 are to be considered in parallel. Noting the remarks made in the estimate of efficiency of a parallel system their combined efficiency will be $1 / 2\left(E_{13}+E_{24}\right)$.

Now, let us consider some gear trains with five elements (vertices) i.e. gear trains with three gear pairs. Simplest among them is shown in figure 6 . The component efficiency of the gear train will be as given below.

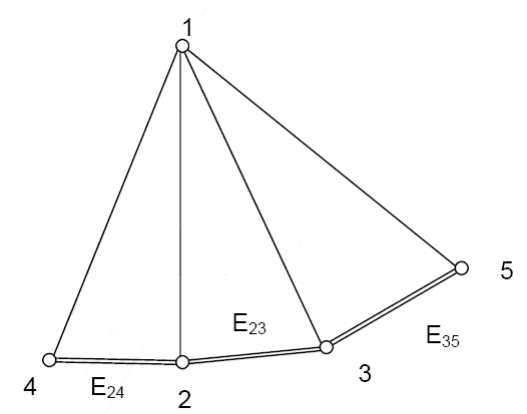

Figure 6. Gear trains with 5 elements - First Type

$$
\mathrm{E}=\mathrm{E}_{23} \cdot \mathrm{E}_{24} \cdot \mathrm{E}_{35}
$$

For comparison, another gear train with a mixed arrangement i.e., both parallel and series, of gear wheels is shown in figure 7 the schematic diagram is shown in figure $7 \mathrm{a}$ while the corresponding graph is shown in figure $7 \mathrm{~b}$.

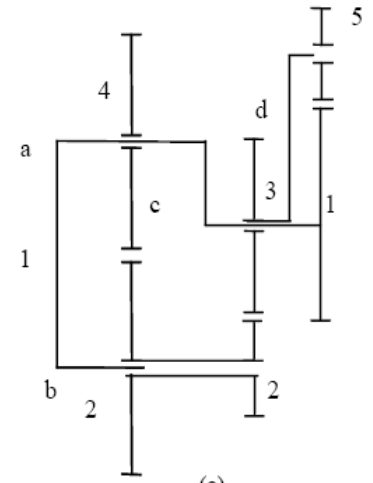

(a)

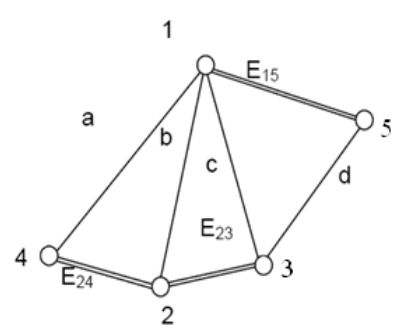

(b)

Figure 7 gear trains with five elements - Second Type

As suggested earlier, the gears 2, 3 and 4 are considered in series so that their $\mathrm{E}_{23}, \mathrm{E}_{24}$. Now, the combined system of gear pairs (4-2-3) should be

$$
1 / 2\left(\mathrm{E}_{15}+\mathrm{E}_{23} \cdot \mathrm{E}_{24}\right) \mathrm{j}
$$

For a clear understanding let us consider gear trains with 6-elements or four gear pairs Figure 8 shows the graphs of such gear trains. With the understanding we have from the previous examples one can see, figure $8(\mathrm{~b})$, that the gear pairs (2-3) and (2-4) are in series and so is the case with gear pairs (1-5) and (5-6). The assembly of the wheels (4-2-3) is then considered to be parallel with the assembly of the wheels (1-5-6). Now the efficiency of the gear train can be written directly. 


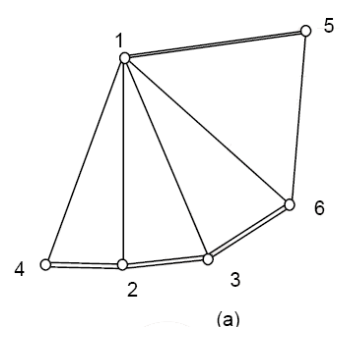

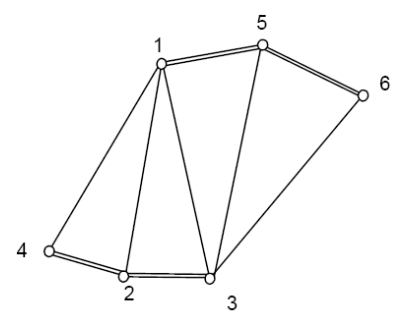

(b)

Figure 8 Gear trains with 6 elements-First Type

$$
\mathrm{E}=1 / 2\left[\left(\mathrm{E}_{23} \cdot \mathrm{E}_{24}\right)+\left(\mathrm{E}_{15} \cdot \mathrm{E}_{56}\right)\right]
$$

For the gear train, figure 8a, the efficiency

$$
\mathrm{E}=1 / 2\left[\left(\mathrm{E}_{15}+\mathrm{E}_{23} \cdot \mathrm{E}_{24} \cdot \mathrm{E}_{36}\right)\right]
$$

As a last example let us consider another gear train which is slightly complicated, figure 9 (a \& b)
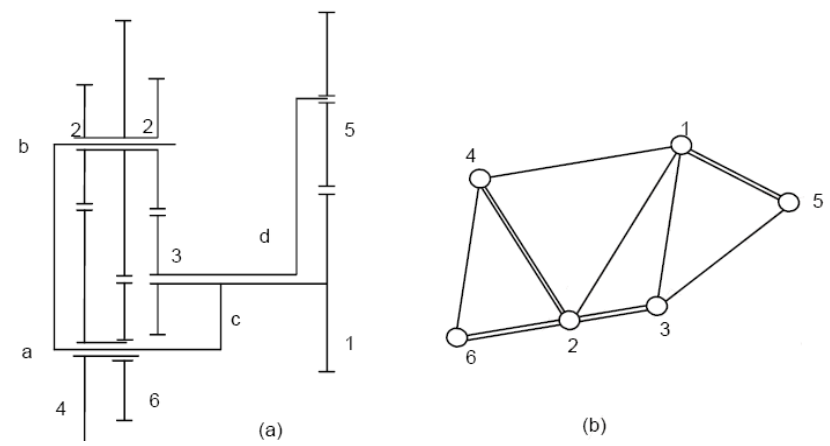

Figure 9. Gear trains with 6 elements-Second Type

Consider the cluster of the gear pairs (2-3), (2-4) and (2-6). The above arrangement suggests that of the three gear pairs, if pairs (2-3) and (2-4) are considered in series then the pair (2-6) is parallel to then. Similarly, the pair (2-3) and (2-6) can be considered in series while the third pair (2-4) is in parallel with them. In general, any two pairs can be taken in series while the third pair is in parallel with them. The efficiencies of all the possible combinations are given below.

Case (i)

Pairs (2-3) and (2-4) are in series and pair (2-6) is in parallel. Then

$$
\begin{gathered}
\mathrm{Ec}=\text { The efficiency of the cluster of gear wheels } 2,3,4 \text { and } 6 \\
=1 / 2\left(\mathrm{E}_{23} \cdot \mathrm{E}_{24}+\mathrm{E}_{26}\right)
\end{gathered}
$$

Case (ii)

Gear Pairs (2-3) and (2-6) are in series and pair (2-4) is in parallel. Then

$$
\mathrm{Ec}=1 / 2\left(\mathrm{E}_{23} \cdot \mathrm{E}_{26}+\mathrm{E}_{26}\right) \text {, }
$$

Case (iii):

Pairs (2-4) and (2-6) are in series and the pair (2-3) is in parallel. Then

$$
\mathrm{Ec}=1 / 2\left(\mathrm{E}_{24} \cdot \mathrm{E}_{26}+\mathrm{E}_{23}\right) \mathrm{j}
$$

In such a case it is safer to take the lowest value of the above three efficiencies, eq.(8-10) and let this be $\mathrm{E}$ min. Now, the net efficiency of the gear train

$$
=\mathrm{E}=1 / 2\left(\mathrm{E}_{\min }+\mathrm{E}_{15}\right)
$$




\section{Conclusions}

- Assignment of equal efficiencies to all the gear pairs enables the comparison of distinct structures. For example structure figure. 3 is better than figure. 2. Similarly, the gear train, figure. 7 is superior to figure.6.

- Specifying the number of teeth on the gear wheels enables estimation of the anticipated efficiency of the gear train.

- In gear trains with equal number of gear pairs, the gear trains with parallely arranged pairs are more efficient.

- Parallely arranged serial pairs, figure.8(b), appear to be inferior to the arrangement in which more pairs arranged in series which in turn are parallel with the remaining gear pairs (not in series), figure.8(a).

- Gear trains with a cluster of wheels figure.9 is better than the trains figure.8.

\section{References}

C. H. Hsu, \& J. J. Hsu. (1997). An efficient methodology for the structural synthesis of geared kinematic chains. Mech. Mach. Theory, 1997, vol. 32, pp. 957-973. http://dx.doi.org/10.1016/S0094-114X(96)00081-X

F. Buchsbaum, \& F. Freudenstein. (1970). Synthesis of kinematic structure of geared kinematic chains and other mechanisms. J. Mechanisms,vol. 5, pp. (357-392). http://dx.doi.org/doi:10.1016/0022-2569(70)90068-6

J. E. Shigley, Miscke. (2003). Mechanical Engineering Design (SI Units), Sixth edition, Tata Mc Graw Hill, p. 870.

L. W. Tsai. (1989). On the Conceptual Design of a Novel Class of Robot Configurations, Trans ASME J. Mech. Trans. Auto. Design, vol. 109, pp. 329- 336. http://dx.doi.org/10.1115/1.3258798

M. F. Spotts. Mechanical Design Analysis, Prentice-Hall, Eagle wood cliffs, NJ, pp. 187-188.

R. Ravisanker, \& T. S. Mruthyunjaya. (1985). Computerized synthesis of the structure of geared kinematic chains. Mech. Mach. Theory, vol. 20, pp. 367-387. http://dx.doi.org/10.1016/0094-114X(85)90042-4 